\title{
Patient-physician relationship and ante-natal seeking behaviour in public hospitals
}

\author{
${ }^{1}$ Aluko-Arowolo S.O, ${ }^{2}$ Ogundimu Ayobami O, ${ }^{3}$ Solarin Thomas M. \\ ${ }^{1}$ Department of Sociology and Psychology, Olabisi Onabanjo University, Ago-Iwoye, Nigeria \\ ${ }^{2}$ Social Governance and Policy Research Department, NISER, Ojoo Ibadan, Nigeria \\ ${ }^{3}$ Primary Health Care, ljebu-Ode Local Government, Ogun State, Nigeria \\ Corresponding authors' email: ogundimuayobami@gmail.com
}

\begin{abstract}
This study examines the roles of patient-physician relationship as the underpinning factor that may inhibit or motivate early booking of pregnancy among women in ljebu, Ogun State. The study utilizes a triangulation method of survey including in-depth interview. ljebu-Ode carries $32.2 \%(141)$ and ljebuIgbo $64.8 \%(259)$ of the total sample representing the urban and rural populace. A structured questionnaire was administered to randomly select 400 consenting women attending ante-natal clinics session in equally randomly selected hospitals in ljebu-Ode and ljebu-Igbo. In addition, ten percent of the women were selected through a stratified sampling method for in-depth interview. And ten in-depth interviews (IDIs) were conducted among gynaecologist, nurses and other health workers. The study identifies a non-cordial relationship between physicians and ante-natal patients which in turn serves as a reason for late booking of pregnancy and irregular attendance of pregnant women at ante-natal care sessions. Qualitative data reveal that many of the pregnant women stay away from ante-natal care because of the uncooperative manner of the physician by not giving enough attention and the use of abusive, vague and ambiguous words which are not discernable to barely literate patients. The study concludes that early booking of pregnancy by women is influenced by their closeness and mutual relationship with their physician. And therefore suggests that physicians should pay due diligence to the relationship that exists between them and patients and the appropriate organs of government, agency and non-governmental organizations (NGOs) should encourage the dissemination of maternal health education.
\end{abstract}

Keywords: Patient-Physician, Relationship, Ante-natal seeking behaviour, Public Hospitals, ljebu people.

\section{INTRODUCTION}

Health workers and healthcare consumers relationship forms one of the foundations of contemporary medical ethics and practices. In other words, the degree of relationship and mutual reciprocity between the patient and physician is important to both the health givers and consumers in enhancing the accuracy of diagnosis and increasing the patient's knowledge about the disease (Maguire 2010; Lupton, 2000; Horobin, 1975; Freidson, 1975). However, health providers in the formal sectors have been described as rude, uncaring, unkind, and unsympathetic by patients generally and specifically pregnant women in Nigeria and elsewhere in the developing countries (Aluko, 2008; Symke, 1995). In the situation of non-cordial relationship, the physician's ability to make a full assessment may be compromised and the patient is more likely to distrust the diagnosis and proposed treatment. To be sure, one of the most important indicators of quality life in any society is the health status of the population. In essence healthcare consumption is linked therefore, not only to the levels of diagnosis, treatment and prognosis, but the level of relationship between the healthcare provider(s) and consumers. The quality of interaction between health workers and healthcare consumers is highly important and, of great impetus for unhindered access to care (Jegede, 2010; Erinosho, 2006; Safe Motherhood Fact 
Sheet - SMHFS, 2000; Harrison, 1997; Bloorand Harobin, 1975). The better the relationship in terms of mutual respect, knowledge, trust, shared values and understanding about disease and life, and time available, the better will be the amount and quality of information about the patient's disease treatment from both directions of physician and patients (Germov, 2000(a)).

Health seeking behaviour of pregnant women differs from society to society, and across socio-economic categories; while, those who are well placed in terms of income and education may have uninhibited relationship with physicians - often as a result of respect based on mutual reciprocity. Those within the low socio-economic status (SES) may not be that opportune. However, irrespective of SES, one of the most revered principles in medical ethics has been that physicians should be exclusively devoted to the best interests of their patients. But this principle is assumed to be at variance and affect negatively those who do not have the socio-economic wherewithal to book their pregnancies at the right time and follow medical regimen strictly. Although, physicians are required to do everything that they believe may benefit their patients without regard to costs or other societal considerations. But, this is not always the case.

In essence, delay access to care due to what can be termed as "anticipatory fear of physician" may result in late booking or non-booking for ante-natal care (ANC), poor obstetric care and other maternal health risks with consequences of complications, injury or death. Death of a pregnant woman sometimes and/or complications can be prevented through appropriate and timely use of health services. This is not always the case in ljebu, south western Nigeria, due to non utilization and poor utilization of health services as only 37 percent of pregnant women deliver in the orthodox health facilities (National Demography and Health Survey - NDHS, 2008). This study therefore examines mainly the roles of physician and ante-natal care patients' relationship as the underpinning factor that may inhibit early booking of pregnancy and also to examine patients' perceptions of the attitude of physician as determinant factors for antenatal seeking behavior.

It is believed that the study will contribute to policy focus on safe motherhood in Nigeria and help in developing a platform on which strategy for holistic solution can be predicated.

\section{Justification for the Study}

This study examines the process and features of the physicians and ante-natal patients' relationship. Relationship between health workers and maternal health patients is becoming an increasingly issues in SouthWestern Nigeria on why there may be delay in the booking of pregnancy, or, non-booking. This has inspired researchers in medical and social sciences to consider the implications of this relationship and at ensuring successful ante-natal care. However, most of the empirical researches done on physician and health consumers' relationship until now, hardly, have inputs from methods and theories in social sciences. This apart, it is noted that maternal mortality ratio is at $245 / 100,000$ among ljebu women (Ogun state Health Bulletin, 2009), thus maternal health problem is still high in ljebu going by World Health Organisation's acceptable ratio - This may have implications on the Millennium Development Goals (MDGs5) for policy design on maternal health and its implementation.

\section{Scope of Study}

The geographical location for the study was ljebu Division of Ogun State in South Western Nigeria. The study examined various socio-cultural issues associated with ante-natal health care consumption. Health workers and pregnant women of various stages/trimesters of pregnancy with different socio-economic status, gender, educational levels, religious affiliations and marital status were examined in the study to understand relationship between physicians and ante-natal care patients.

\section{Literature Review and Theoretical Orientation}

Theories and models in social sciences are noted to be the foundation of socio-cultural and ethical analysis of health related issues because they represent the view points from which guidance can be obtained on health care consumption and the pathways to decision making. On the other hand, analysis of health policy commitment for information and/or education, services, management and motivation for safe motherhood shows many gaps which needed to be filled. Maternal health poses challenges not just for patients alone but also for obstetrician/ gynaecologists including general practitioners, and others who are providing healthcare for people with maternal health problem. Especially, when booking and medical history are not harnessed on time.

Across the world, health workers and health consumers' relationship is a central index to the healthcare practice ((Maguire 2010). This includes delivery of expected quality of health care in terms of prophylactic and therapeutic dimensions of medicine for illness, sickness and disease. This entails physicians having professional rapport with patients, uphold patients' dignity, and respect for their privacy. On the other hand patients must have confidence in the competence of their physicians and must feel that they can confide in him or her. In different societies, periods, and cultures, different values may be assigned different priorities as in the case of pregnant health care utilization (Orubuloye \& Ajakaiye, 2002). The physician and patient relationship therefore 
can be analysed from the perspective of ethical concern, in terms of how well the goals of malfeasance, beneficence, autonomy, equity and justice are achieved. This would possibly reveal certain elements that may act as catalyst to conflict or non-cordial relationship and which may not allow pregnant person to follow medical prescriptions to the letter or adapt to regimen of patient roles strictly. The source(s) of the conflict may be understood further from the assumptions held by the caregivers, which assumed that, sick persons should use their own judgment as when it is appropriate to seek medical advice but, on the other hand, patients are later expected to defer to the physician judgment when undergoing medical treatment (Bloor \& Horobin, 1975; Orubuloye et al, 2002; Murphy, Elaine, Ringleim \& Karim, 2006). Often the conflicting expectations place the patients in a double-bind situation. However, the quality of the patient - physician relationship is important to both parties. The better the relationship in terms of mutual respect, knowledge, trust, shared values and perspectives about disease and life, and time available, the better will be the amount and quality of information about the patient's disease treatment in both directions. This, on the other hand enhances accuracy of diagnosis and increasing the patient's knowledge about the illness; which ultimately affects compliance and prognosis. On the contrary, where such a relationship is poor the physician's ability to make a full assessment is compromised and the patient is more likely to distrust the diagnosis and proposed treatment (en.wikipedia .org/wiki/ Doctor-patient relationship; 2010), that is, in this case, the ante-natal booking and treatment prescribed.

Maguire (2010) citing the work of Stewart and Roter (2001) describes the doctor/patient relationship as having four patterns: paternalistic, consumeristic, default and mutuality. The paternalistic approach is typified by physician - centred style. It relies on closed questions designed to elicit yes or no answers. The health giver will tend to use a disease - centred model and be focused on reaching a diagnosis, rather than the patient's unique experience of illness. The consumeristic pattern holds that patient knows exactly what they want and forces the doctor into a patient-centred approach. The default pattern is a situation where the patient - centred fails and the physician is trying to relinquish control but the patient is unwilling to accept it and at it results into an impasse.

The fourth pattern is a situation where the doctor uses open questions to encourage the patients to talk about their complaints. The approach relies on taking time to listen and trying to understand the patient's point of view. The belief that the physician and patient relationship is fundamentally reciprocal does not hold true all the time (Bloor and Horobin, 1975; Freidson, 1975 and Maguire, 2010). The physician may be viewed as superior to the patient, because the physician has the knowledge and credentials and most often the one on ground. The relationship can also be complicated by the patient's suffering and limited ability or lack of exposure. This is potentially injurious to effective communication that engenders proper health care utilization; resulting in a state of desperation and dependency on the part of health care seekers (Maguire, 2010). Often the interaction is shaped by their differing social roles, status, environment and different needs. These are often the underpinning factors to illness behaviour

\section{Educational Factors}

Nigerians who are educated are likely to utilize orthodox/ western-style health care services than the non-literate during ill- health. Although those with formal western education are also in suzerainty with magico-religious factors in their concept of disease (Aluko-Arowolo, 2006; 2012; Aluko-Arowolo \& Ogundimu, 2015). In this respect, both the literate and the non-literate behave alike and usually seek help from traditional healers when in a critical health situation. The choice of traditional healers among non-literate patients is further encouraged by the belief that they (i.e. these healers) are efficient and their medicines are efficacious to cure what may be considered as metaphysical health problems.

Second, non-literate Nigerian patients prefer to seek treatment in the compounds of traditional healers rather than in the premises of cosmopolitan western-style health care facilities largely because they find formalities like queuing for cards, registration, physical examinations, etc. in the latter cumbersome, strange, and seemingly alienating (Erinosho, 2006). This is in contrast to formally educated patients who find the environment of orthodox health care facilities attractive, conducive, and acceptable. Others are gender and religion which also affect maternal health care consumption.

\section{Gender Factors}

Health seeking behaviour of women in generally and pregnant women in particular is impelled by patriarchal norms - in terms of decision making by the husband. Nigerian women may not seek immediate help from health care agents when they are to book their pregnancies and where to deliver the babies unless they obtain formal permission from their spouses (Chiwuzie and Okolocha, 2001). Others are religious dogma where Islam, for instance, frown at male physicians dotting female patients (Oruboye et al, 2002; Aluko, 2008).

Action taken, or, to be taken on the use of health care facilities during ill health or pregnancy period may well depend on perception of disposition of physician's friendliness, efficiency and effectiveness of the services being provided, and on how well-suited is therapeutic intervention to the social status of users/ health consumers. Action therefore is presupposed to be between one person/group and the other/others. 


\section{Theoretical Orientation: Weber's Social Action Theory}

Weber (1947) sees action as the ultimate reference point for one's ideas of man/woman and sees human beings as a compendium of basic data of a systematic whole with a particular emphasis put on focal question about social interaction (Rossides, 1978; Gerth \& Mill, 1979; Jegede, 1995 and Ritzer, 2008). He differentiated between action and purely reactive behaviour (Turner, 1983). The concept of behaviour is reserved, then as now, for automatics behaviour that involves no thought processes. A stimulus is presented and behaviour occurs, with little intervening between stimulus and response. Such behaviour was not of interest in Weber's theory. He was concerned with action that clearly involved the intervention of thought processes (and the resulting meaningful action, such as physician and patient relationship) between the occurrence of a stimulus and the ultimate response. To Weber, action is a unit act and action, as it were, is an outcome of relationship between actors.

To put this slightly differently, action is said to occur when individuals attach subjective meanings to their action. Therefore, an important way to understand human behaviours is to understand the motives behind individuals' action. This is can be understood through individuals' roles and functions. However, to understand an actor's behaviour, one must not only understand the explicit/expressive meaning of action, but, also the implicit/inexpressive meaning of action. It goes without saying that an actor must have goal or the end and the method (means) of achieving this end. However, in choosing the means of achieving this goal, the action may be subjected to intervening variables, such as social, cultural, environment and personal beliefs. In other word, action involves useful and practical consideration between competing alternatives and for specific ends.

As a way of illustration, a pregnant woman in her effort to seek for ANC and safe delivery may decide to accept both the goal and the end. That is, to have safe delivery without unpleasant outcomes by accepting the method/means - which is the adequate utilization of health services in orthodox hospital without considering physician action - and this may be competing with her resolve to have safe delivery. In all, early booking, late booking or non booking of pregnancy depend on the action expected between the pregnant woman and healthcare providers.

\section{Method and Instrument}

ljebu people occupy a total number of six local Government areas out of the twenty local governments in Ogun state, Nigeria. - ljebu-Ode, Odogbolu, ljebu-North, ljebu North East, ljebu East and Ogun Waterside - out of these, two Local Government Areas were selected purposively - ljebu North and ljebu Ode - representing rural and urban populace respondents respectively. The population of ljebu-Ode and ljebu-Igbo were 9,985 and 18,365 respectively. This makes the total population to be 28,350 , with ijebu-Ode having $35.2 \%$ and ljebu-Igbo $64.8 \%$. There are 23 and 14 public health facilities in ljebu North and ljebu-Ode respectively. $50 \%$ of the total numbers of these hospitals were selected through a simple random sampling to accommodate major hospitals and maternities, as some residences and settlements are bereft of health care centres.

A purposive and simple random sampling was adopted to select the respondents included in the study. In addition, ten percent of the women were selected through a stratified sampling method for in-depth interview. And ten in-depth interviews (IDIs) were conducted among gynaecologist, nurses and other health workers Data collected were analyzed with chi-square statistical method to interpret and test for the hypothesis. The study population was the pregnant women between 15 to 49 years respectively.

\section{Sample Size}

This was done using the Yaro Yamane's technique as stated below. This result gotten using this formula is 394.4 and this was approximated to 400 in a case of attrition. ljebu-Ode carries $32.2 \%(141)$ and ljebu-Igbo $64.8 \%$ (259) of the total sample. The formula stated as-

$$
n=\frac{N}{1+N}\left(\theta^{2}\right)^{2}
$$

Where; $n=$ desired sample size,

$N=$ Population size under study

$\mathrm{E}=$ Level of significance of error. Assumed to

be $5 \%$

Therefore

$I=$ Constant

$$
\begin{aligned}
N & =? \\
N & =28,350
\end{aligned}
$$

Sample size $(n)=\underline{28,350}$

$$
\begin{aligned}
& \mathrm{N}=\frac{28,350}{7+28,350(0.05) 2} \\
& 71.875 \\
& \mathrm{n} \quad=394.4 \text { subjects which was approximated to }
\end{aligned}
$$
400 to give room for attrition.

An interviewer-administered questionnaire was designed and used to collect respondents' bio-data and data relevant to the study objectives. The study instruments elicit respondents' antenatal seeking behaviour, respondents' perception of the physician and relationship with the physician as a factor underpinning their antenatal seeking behaviour. 
Table 1: Socio- Demographic Characteristic of Respondents

\begin{tabular}{|c|c|c|c|c|}
\hline$S / N$ & QUESTIONS & CATEGORIES & FREQUENCY & PERCENTAGE (\%) \\
\hline \multirow[t]{5}{*}{1.} & \multirow[t]{5}{*}{ Age } & $15-24$ & 103 & 26.1 \\
\hline & & $25-34$ & 226 & 57.2 \\
\hline & & $35-44$ & 65 & 16.5 \\
\hline & & 45 and above & 1 & 0.3 \\
\hline & & Total & 395 & 100.0 \\
\hline \multirow[t]{4}{*}{2} & \multirow[t]{4}{*}{ Religion } & Christianity & 228 & 57.7 \\
\hline & & Islam & 165 & 41.8 \\
\hline & & Traditional & 3 & 0.5 \\
\hline & & Total & 395 & 100.0 \\
\hline \multirow[t]{6}{*}{3} & \multirow{6}{*}{$\begin{array}{c}\text { Educational } \\
\text { Qualification(s) }\end{array}$} & No formal education & 22 & 5.6 \\
\hline & & Primary school & 37 & 9.4 \\
\hline & & Junior sec. school & 32 & 8.1 \\
\hline & & Senior sec. school & 140 & 35.4 \\
\hline & & Tertiary & 164 & 41.5 \\
\hline & & Total & 100 & 100.0 \\
\hline \multirow[t]{5}{*}{4} & \multirow[t]{5}{*}{ Occupation } & No occupation & 52 & 13.2 \\
\hline & & Civil/Public servant & 121 & 30.6 \\
\hline & & Trading & 154 & 39.0 \\
\hline & & Menial/petty job and others & 68 & 17.2 \\
\hline & & Total & 395 & 100 \\
\hline \multirow[t]{6}{*}{5} & \multirow[t]{6}{*}{ Ethnic group } & Yoruba & 344 & 87.1 \\
\hline & & Igbo & 23 & 5.8 \\
\hline & & Deltan(Benin, Isoko e.t.c) & 15 & 3.8 \\
\hline & & Benue(Igede, Agatu e.t.c) & 5 & 1.3 \\
\hline & & Hausa/Fulani & 8 & 2.8 \\
\hline & & Total & 395 & 100.0 \\
\hline \multirow[t]{6}{*}{6} & \multirow[t]{6}{*}{ Total income Per Month } & $0-\# 9,000$ & 134 & 37.9 \\
\hline & & $\# 10,000-\# 19,000$ & 104 & 29.4 \\
\hline & & $\# 20,000-\# 29,000$ & 48 & 13.6 \\
\hline & & $\# 30,000-\# 39,000$ & 27 & 7.6 \\
\hline & & $\# 40,000$ \& above & 41 & 11.5 \\
\hline & & Total & 354 & 100.0 \\
\hline
\end{tabular}

\section{RESULTS}

A total of numbers of 395 instruments (a response rate of $98.75 \%$ ) were valid from 400 administered. Table 1 above presents the socio-demographic characteristics of respondents. The table reveals that respondents between the ages of $15-24$ years were $103(26.1 \%)$ while, 226 $(57.2 \%)$ of them were between $25-34$ years, $65(16.5 \%)$ were between $35-44$ years and 45 years and above were $1(0.2 \%)$. This indicates that majority of the women were between the age range of 25-34 years. In the distribution of respondents' religion, $228(57.7 \%)$ of the respondents are Christians, $165(41.8 \%)$ are Muslims and $2(0.5 \%)$ are traditional worshippers.
On the educational qualification, the table shows that, most of the respondents $164(41.5 \%)$ have tertiary education, $37(9.4 \%)$ had primary school education, $32(8.1 \%)$ and $140(35.4 \%)$ had junior and senior secondary school education respectively while 22(5.6\%) had no formal education. It was further revealed that $121(30.6 \%)$ and $154(39.0 \%)$ of the respondents were mainly civil servants and traders respectively, 96 (24.3\%) were into menial jobs while the rest $52(13.2 \%)$ had no occupation. The distribution of respondents' ethnic groups shows that a larger proportion of the respondents $344(87.1 \%)$ are Yoruba, while 23(5.8\%), 15(3.8\%), $5(1.3 \%)$ and $8(2.0 \%)$ were Igbos, Deltans (Benin, Isoko e.t.c), Benue(Igede, Agatu e.t.c) and Hausa/Fulani 
Table 2: Antenatal seeking behavior of respondents

\begin{tabular}{|c|c|c|c|c|}
\hline S/N & Variables & responses & FREQUENCY & PERCENTAGE (\%) \\
\hline \multirow[t]{5}{*}{1.} & \multirow{5}{*}{ How old is your pregnancy? } & $0-3$ & 43 & 10.9 \\
\hline & & $4-6$ & 168 & 42.5 \\
\hline & & $7-9$ & 157 & 39.7 \\
\hline & & $9+$ & 27 & 6.8 \\
\hline & & Total & 395 & 100.0 \\
\hline \multirow[t]{3}{*}{2} & \multirow{3}{*}{ Do you come to the Clinic? } & Yes & 129 & 32.7 \\
\hline & & No & 266 & 67.3 \\
\hline & & Total & 395 & 100.0 \\
\hline \multirow[t]{6}{*}{3} & \multirow[t]{6}{*}{$\begin{array}{l}\text { How often do you visit physician for } \\
\text { ANC }\end{array}$} & $\begin{array}{l}\text { When given } \\
\text { appointment }\end{array}$ & 23 & 5.8 \\
\hline & & Once in a month & 19 & 4.8 \\
\hline & & Once in a trimester & 293 & 73.4 \\
\hline & & Once in 6 months & 15 & 4.1 \\
\hline & & $\begin{array}{l}\text { Once during } \\
\text { pregnancy }\end{array}$ & 47 & 11.9 \\
\hline & & Total & 395 & 100.0 \\
\hline
\end{tabular}

respectively. On the income of the respondents, a larger percentage of $134(37.9 \%)$ were earning between 0$\# 9,000,104(29.4 \%)$ of the respondents earned between \#10,000 - \#19,000. Others 48 (13.6\%), 27 (7.6\%) and 41 $(11.5 \%)$ of the respondents were earning between $\# 20,000$ - \#29,000, \#30,000-\#39,000, \#40,000 above respectively.

Table 2 above shows how often the respondents visit the hospital for ante natal care. $10.9 \%$ of the respondents are within their first trimester, $42.5 \%$ are within their second trimester, and $39.7 \%$ are within their third trimester while $6.8 \%$ respondents' pregnancy is over nine months. This indicates that majority of respondents are between second and third trimester. On how often the respondents go for ANC, $32.7 \%$ often go for ANC while majority of $67.3 \%$ do not often go for ANC. Respondents were probed further on how often they visit physician for ANC, over $70 \%$ of the respondents visit their physician once in a trimester - making total number of ANC attendance during the pregnancy duration only three times, while $5.8 \%$ of them only go for ANC when given appointment, $4.8 \%$ of the respondents visit the physician once in a month, $4.1 \%$ go for ANC once in six months, while, $11.9 \%$ of the respondents go for ANC once during the pregnancy.

On the antenatal seeking behaviour of respondents as shown in table 3, however, $117(29.6 \%)$ and $264(66.8 \%)$ of the respondents respectively described how their physician treated/related with them during ANC. Respondents were further questioned on how can they rate the attitude of their physician/health worker, $261(66.1 \%)$ of the respondent rated their physician's attitude as poor while $97(24.6 \%)$ and $37(9.4 \%)$ rated their physician's attitude as good and fair respectively.

The perception of the physician's attitude according to majority of respondents on In-depth Interviews:
The doctors are very friendly, may be because they are male, but these women (i.e. nurses) are not caring at all. They (nurses) sees our condition as no big deal, and with this, they address us anyhow, and atimes, I feel like I should not come for ANC, unless I experience any complication which my mother-in-law's herbs/concoction cannot handle. I feel maybe because these nurses are older than me (KIls with pregnant women, May, $15^{\text {th }} 2014$ )

However, the result of respondents who poorly rated their physician's attitude were further questioned by asking them which of the physician/health worker. 29(7.3\%) were doctors, a larger proportion of $213(53.9 \%)$ were the nurses while the rest $24(6.1 \%)$ were the pharmacist. Respondents attributed various negative attitudes to the physician/health worker which they detest. 4(1.5\%), $7(2.6 \%), 22(8.3 \%), 84(31.6 \%)$ and $125(47.0 \%)$ detest time waiting for registration, doctor not listening before prescription, doctor not explaining his/her findings, waiting time to see the doctor/nurses and uncooperative manner of physician especially the nurses while $24(9.0 \%)$ detest and directed the too long time of waiting at the pharmacy to the pharmacist. A larger proportion of $47.0 \%$ attributed uncooperative manner of physician especially the nurses as the attitude they detest. This corroborates with the responses given by majority of respondents on in-depth interviews:

The attitude of the physician especially the nurses is nothing to write home about, they address one derisively as if being pregnant is a sin/an offence. A times, they compare one with animal by saying 'oyun ki lo ni, ti enikan o ni ri, a sa $n$ ri 
Table 3: Patients' Perception about their Physician

\begin{tabular}{|c|c|c|c|c|}
\hline $\mathrm{S} / \mathrm{N}$ & Variables & Responses & FREQUENCY & PERCENTAGE (\%) \\
\hline \multirow[t]{4}{*}{1.} & \multirow{4}{*}{$\begin{array}{l}\text { Does your physician } \\
\text { treat/relate with you well? }\end{array}$} & Yes & 117 & 29.6 \\
\hline & & No & 284 & 66.8 \\
\hline & & Indifferent & 14 & 3.5 \\
\hline & & Total & 395 & 100.0 \\
\hline \multirow[t]{4}{*}{2} & \multirow{4}{*}{$\begin{array}{l}\text { How can you rate the } \\
\text { attitude of the physician? }\end{array}$} & Good & 97 & 24.6 \\
\hline & & Fair & 37 & 9.4 \\
\hline & & Poor & 261 & 66.1 \\
\hline & & Total & 395 & 100.0 \\
\hline \multirow[t]{4}{*}{3} & \multirow{4}{*}{$\begin{array}{l}\text { Which of the health } \\
\text { workers? }\end{array}$} & Doctor & 29 & 10.9 \\
\hline & & Nurse & 213 & 80.1 \\
\hline & & Pharmacist & 24 & 9.0 \\
\hline & & Total & 266 & 100.0 \\
\hline \multirow[t]{7}{*}{4} & \multirow{7}{*}{$\begin{array}{c}\text { Which attitude of the } \\
\text { physician/health worker did } \\
\text { you detest? }\end{array}$} & Time for registration & 4 & 1.5 \\
\hline & & $\begin{array}{l}\text { Waiting time to see the } \\
\text { doctor }\end{array}$ & 84 & 31.6 \\
\hline & & $\begin{array}{l}\text { Waiting time at the } \\
\text { pharmacy }\end{array}$ & 24 & 9.0 \\
\hline & & $\begin{array}{l}\text { Uncooperative manner } \\
\text { of physician }\end{array}$ & 125 & 47.0 \\
\hline & & $\begin{array}{l}\text { Doctor/nurses not } \\
\text { listening before } \\
\text { prescription }\end{array}$ & 7 & 2.6 \\
\hline & & $\begin{array}{c}\text { Doctors not explaining } \\
\text { his/her findings }\end{array}$ & 22 & 8.3 \\
\hline & & Total & 266 & 100.0 \\
\hline
\end{tabular}

oyun ninu eran' meaning "what is the big deal in being pregnant, after all animal do get pregnant". They use all sort of unwelcoming words. (KIls with pregnant women, May, $15^{\text {th }}$ 2014)

This uncooperative manner was stated otherwise by physicians - in the hospitals, as IDIs with them were summarized thus:

...pregnant women shows lackadaisical attitude towards their condition. What they do is that, attendance is generally satisfactory in terms of them (pregnant women) booking their pregnancy but, immediately after booking, they don't come for proper routine check-up. They are also noted for not adhering to their maternity day as at when necessary until they experience complication as a result of engaging in self-medication. One feels at loss and not comfortable whenever they put on this act and this in turn make them to see us as not friendly, but we can't pretend/act in cordiality with them when they behave this way

(IDls with Drs/Nurses K, H, A \& O, in July, 2014)

Table 4 below shows the relationship between physician and antenatal patients. $24.8 \%$ and 6.8 of the respondents describe their relationship with their physician as cordial and very cordial respectively, $6.1 \%$ express a strain relationship while a larger proportion of $62.3 \%$ describe their relationship with their physician as not cordial. However, the table further reveals that a larger proportion of $65.1 \%$ of the respondents describe their non-cordial relationship as a reason for not attending regular ANC, in turn serving as a factor for larger number of $293(73.4 \%)$ of the respondents to attend ANC once in a trimester, interaction, accordingly plays a significant role in healthcare of pregnant women, according to majority of respondents on in-depth interviews:

.... the non-cordial relationship between pregnant women and the physician plays a very negative role during pregnancy because one hardly comes for ante-natal care as we detest the way 
Table 4: Patient-Physician Relationship and Antenatal Seeking Behaviour

\begin{tabular}{|l|c|c|c|c|}
\hline S/N & Variables & Responses & FREQUENCY & PERCENTAGE (\%) \\
\hline 1. & How will you describe the & Cordial & 98 & 24.8 \\
\cline { 3 - 5 } & \multirow{2}{*}{$\begin{array}{c}\text { relationship between you } \\
\text { and your physician? }\end{array}$} & Very cordial & 27 & 6.8 \\
\cline { 3 - 5 } & & Strain & 24 & 6.1 \\
\cline { 3 - 5 } & & Not cordial & 246 & 62.3 \\
\cline { 3 - 5 } & & Total & 395 & 100.0 \\
\hline \multirow{2}{*}{2} & \multirow{3}{*}{$\begin{array}{c}\text { How can you rate the } \\
\text { attitude of the physician? }\end{array}$} & Yes & 257 & 65.1 \\
\cline { 3 - 5 } & & No & 126 & 31.9 \\
\cline { 3 - 5 } & & Indifferent & 12 & 3.0 \\
\cline { 3 - 5 } & & Total & $\mathbf{3 9 5}$ & $\mathbf{1 0 0 . 0}$ \\
\hline
\end{tabular}

Table 5: Showing cross tabulation of patient-physician relationship and ante-natal health seeking behavior

\begin{tabular}{|l|c|c|c|c|}
\hline \multirow{2}{*}{$\begin{array}{l}\text { How will you describe the } \\
\text { relationship between you and your } \\
\text { physician? }\end{array}$} & \multicolumn{4}{|c|}{ Could this be the reason for you not coming for regular } \\
\cline { 2 - 5 } & Yes & No & Indifferent & Total \\
\hline Cordial & 3 & 88 & 7 & 98 \\
\hline Very cordial & 3 & 23 & 1 & 27 \\
\hline Strain & 19 & 5 & 0 & 24 \\
\hline Not cordial & 232 & 10 & 4 & 246 \\
\hline Total & $\mathbf{2 5 7}$ & $\mathbf{1 2 6}$ & $\mathbf{1 2}$ & $\mathbf{3 9 5}$ \\
\hline
\end{tabular}

Chi-Square = 298.557; df = 6; Sig. $(2$-sided) 0.73

they use abusive words, innuendoes and abrasive on us, so we prefer not to attend ANC, unless if complication arises or we wait until we are approaching delivery (KIls with pregnant women, May, $15^{\text {th }}$ 2014)

\section{Test of Hypothesis}

There is significant relationship between patientphysician relationship and ante-natal health seeking behaviour"

\section{Interpretation of Findings}

Since the chi-square calculated value $\left(x^{2}\right)$ of 298.557 is greater than the chi-square table value $\left(x^{2}\right) \mathrm{t}$ of 12.592 , we reject the null hypothesis which says there is no significant relationship between patient-physician relationship and ante-natal health seeking behaviour and accept the alternative hypothesis that says there is significant relationship between patient-physician relationship and ante-natal health seeking behaviour.

\section{DISCUSSIONS OF FINDINGS}

Maternal events in ljebu, South-western, and elsewhere in Nigeria is at a crisis point at maternal mortality ratio of $245 / 100,000$. The quality of interaction between health workers and healthcare consumers in general is highly important and, of great impetus for unhindered access to care (Jegede, 2010; Erinosho, 2006; Safe Motherhood Fact Sheet - SMHFS, 2000; Harrison, 1997; Bloor \& Harobin , 1975). The study situated the relationship of 395 pregnant women with their physician as a factor influencing early booking of pregnancy and utilization of ante-natal healthcare. Majority $(66.1 \%)$ of the respondents described the attitude of the physician/health worker as poor and over $80 \%$ of this poor attitude identified by respondents was directed to be as a result of the attitudes of nurses. This can be linked to Aluko (2008) and Symke's, study (1995) in which they posited that, health providers in the formal sectors generally and specifically on pregnancy matters in Nigeria and elsewhere in the developing countries have been described as rude, uncaring, unkind, and unsympathetic.

Majority $(62.3 \%)$ of the respondents described their 
relationship with their physician(particularly the nurses) as non-cordial and perhaps as a barrier constraining ante-natal healthcare utilization, as majority of the respondents identified engaging in abusive words/uncooperative manner of physician(especially the nurses) and the waiting time to see the doctor as the attitude which they detest. This correlates with Germov's study (2000), in which he posited that, the better the relationship in terms of mutual respect, knowledge, trust, shared values and understanding about disease and life, and time available, the better will be the amount and quality of information about the patient's disease treatment from both directions of physician and patients. The result from the chi square analysis showed a significant relationship between patient-physician and antenatal seeking behaviour as those who have a noncordial relationship $(62.3 \%)$ with their physician saw it as reason for not going regularly for their ANC.

This perhaps reflects in their maternal health-seeking behavior, as over $70 \%$ of them only go for ANC once in a trimester and $11.9 \%$ of them go for ANC once throughout the pregnancy period. The findings go in line with the studies of Maguire 2010; Lupton, 2000; Horobin, 1975; Freidson, 1975 that, the degree of relationship and mutual reciprocity between the patient and physician is important to both the health givers and consumers in enhancing the accuracy of diagnosis and increasing the patient's knowledge about the disease. In the situation of non cordial relationship, the physician's ability to make a full assessment may be compromised and the patient is more likely to distrust the diagnosis and proposed treatment.

\section{CONCLUSION}

This study specifically examined pregnant women's relationship with their physician and ante-natal seeking behaviour. The study revealed that there is a significant relationship between patient-physician relationship and ante-natal seeking behaviour. It was found out that majority of the pregnant women describe the attitude of their physician as poor with majority of this poor attitude caused by the nurses, in turn resulting to a non-cordial relationship and acts as barrier for regular ante-natal health seeking behaviour. This is to say that, action taken, or, to be taken on the use of health care facilities during ill health or pregnancy period may well depend on perception or disposition of physician's friendliness, efficiency and effectiveness of the services being provided, and on how well-suited is therapeutic intervention to the social status of users/ health consumers. It is therefore suggested that due diligence must be paid by the physician(s) to relationship being exhibited in other not to deter health users from appropriate maternal care, timely booking for ANC, and effective maternal health care. In addition health education must be disseminated by the appropriate organs of government, agency and nongovernmental organizations.

\section{REFERENCES}

Aluko-Arowolo SO \& Ogundimu, (2015). Residence Location and ante-natal healthcare utilization in selected public and private hospitals in ljebu, southwestern Nigeria:Procedia-Social and behavioural sciences vol.185 May 307 - 313.

Aluko-Arowolo SO (2012). Culture and Health of People of Nigeria" in: A.S. Jegede, O. A, Olutayo, OO Omololu and BE Owumi (Eds.) Peoples and Cultures of Nigeria. Department of Sociology, University of Ibadan, Ibadan Pp. 229 - 240.

Aluko-Arowolo SO (2006). The Medico-Spiritual and Historical Origin of Malaria Disease in T Falola and MM Heaton (Eds.) Traditional and Modern Health System in Nigeria. Africa World Press Trenton and Asmara New York and Eritrea pp.247-256.

Aluko SO (2008). Health seeking behaviour of Pregnant Women among ljebu-Yoruba; an unpublished M.Phil Thesis: Department of Sociology, University of Ibadan, Ibadan Nigeria

Bloor MJ, Horobin GW (1975). The sociology of doctor/patient relationship, Eds

Cox C, Mead A (1975). Sociology of Medical Practice. London: CollierMacmillan. $271-284$

Chiwuzie J, Okolocha C (2001). Traditional belief systems and maternal mortality in a Semi-Urban Community in Southern Nigeria. African Journal of Reproductive Health, 5:1: 75-282.

Erinosho OA (2006). Health Sociology, Ibadan: Sam Bookman

Freidson,Elliot 1975. Dilemmas in the doctor/patient relationship. (Eds) Cox, Caroline and Mead, Adrianne. Sociology of Medical Practice. London: Collier-Macmillan; 285 - 298

Germov J (2000a). Imaging Health Problems as social issues in: Germov John (Ed) Second Opinion: Introduction to Health Sociology (Revisededition): Melbourne, Oxford University Press

Germov J (2000b). Class, Health inequality, and social justice in Germov, John(Ed) Second Opinion: Introduction to Health Sociology(Revised edition): Melbourne, Oxford University Press

Harrison KA (1997). Maternal mortality in Nigeria: the real issues' African J. of Reproductive Health 1.1:7-13

Jegede, A.S. (1995). Socio- cultural factors influencing the use of expanded programme of immunization in the $B$ Health Zone in Nigeria. A PhD Thesis Submitted to the Department of Sociology, University of Ibadan: Ibadan.

Jegede AS (2010). African culture and health (a revised and enlarged edition); Ibadan: BookWright

Lupton D (2000). The body, Medicine, and society in Germov, John(Ed) Second Opinion: Introduction to Health Sociology(Revised edition): Melbourne,Oxford University Press

Maguire, K. 2010. Sociologies of Health and IIIness E- Learning Databank www.medgraphics.cam.ac.uk/shield/

National Demographic and Health Survey (2008). Nigeria Development and Health Survey, Abuja, National Population Commission (NPC)

Nwokocha, E. E. (2004). Socio-cultural factors affecting pregnancy outcome among the Ibani of Rivers State, Nigeria. An Unpublished $\mathrm{PhD}$ thesis submitted to Department of Sociology, University of Ibadan: Ibadan.

Ogun State (2009). Ministry of Health Periodic Health Bulletin 2007 2009 Edition

Orubuloye IO, Ajakaiye DO (2002). Health seeking behaviour in Nigeria. Ibadan, National Institute of Social and Economic Reseach (NISER).

Ritzer G (2008). Sociological theory. ( $7^{\text {th }}$ edition), New York: MacGrawHill.

Rossides DW (1978). The History and Nature of Sociological Theories

Boston HMC. Safe Motherhood Fact Sheet (SMHFS) (2000). Safe motherhood: a community responsibility. Lagos: World Health Organisation (WHO) Publications.

Turner, S.P. (1983). Weber on Action American Sociological Review 48:506-519 